\title{
ROLE OF THE NITRIC OXIDE DONOR LINSIDOMINE CHLORHYDRATE (SIN-1) IN THE DIAGNOSIS AND TREATMENT OF ERECTILE DYSFUNCTION*
}

\author{
MICHAEL C. TRUSS, M.D. \\ ARMIN J. BECKER, M.D. \\ MOHAMAD H. DJAMILIAN, M.D. \\ CHRISTIAN G. STIEF, M.D. \\ UDO JONAS, M.D.
}

From the Department of Urology, Medizinische Hochschule Hannover, Hannover, Germany

\begin{abstract}
Objectives. Recently, nitric oxide was shown to be a mediator of penile erection in men and the nitric oxide donor linsidomine chlorhydrate (SIN-1) was introduced as a novel treatment option in patients with erectile dysfunction. We now present our follow-up results with the intracavernous application of SIN-1.

Methods. One hundred thirteen patients with erectile dysfunction of various etiologies and 10 normal control subjects underwent intracavernous pharmacotesting with $1 \mathrm{mg}$ $\mathrm{SIN}-1$. Of the 113 patients, $71(62.8 \%)$ underwent additional pharmacotesting with a mixture of papaverine $(15 \mathrm{mg} / \mathrm{mL})$ and phentolamine $(0.5 \mathrm{mg} / \mathrm{mL})(\mathrm{P} / \mathrm{P})$. Forty-eight responders to SIN-1 were enrolled in an autoinjection program with this substance.

Results. All normal control subjects had full rigid erections lasting 40 to 70 minutes. Of 113 patients, $78(69 \%)$ had responses sufficient for intercourse with SIN-1, and the other 35 patients $[31 \%$ ) demonstrated inadequate responses. All 44 responders to SIN-1 who also received $P / P$ had erections sufficient for intercourse with $P / P$ in doses of 0.25 to $2 \mathrm{~mL}$ (mean, $0.6 \pm 0.3 \mathrm{~mL}$ ). Six patients $(13.6 \%$ ) had prolonged erections with minimal to moderate doses of P/P. From the total of 27 patients who had erections insufficient for intercourse with SIN-1, $20(74.1 \%$ ) had good responses with 0.25 to $2.0 \mathrm{~mL}$ P/P (mean, $1.5 \pm 0.5 \mathrm{~mL}$ ). One patient (4\%) had a prolonged erection with $1.0 \mathrm{~mL} / \mathrm{P} / \mathrm{P}$. After 10 to 150 injections/patient (total of 1160 injections; mean, 24.1 injections), no significant side effects were noted with SIN-1.

Conclusions. Our data suggest that intracavernous $\mathrm{SIN}-1$ is safe and efficacious in the majority of patients with erectile dysfunction; however, it has a lower smooth muscle relaxing effect than a combination of P/P. The absence of severe side effects, including priapisms, may be explained by the use of a physiologic pathway for induction of the erectile response and the rapid intracavernous decomposition of SIN-1.
\end{abstract}

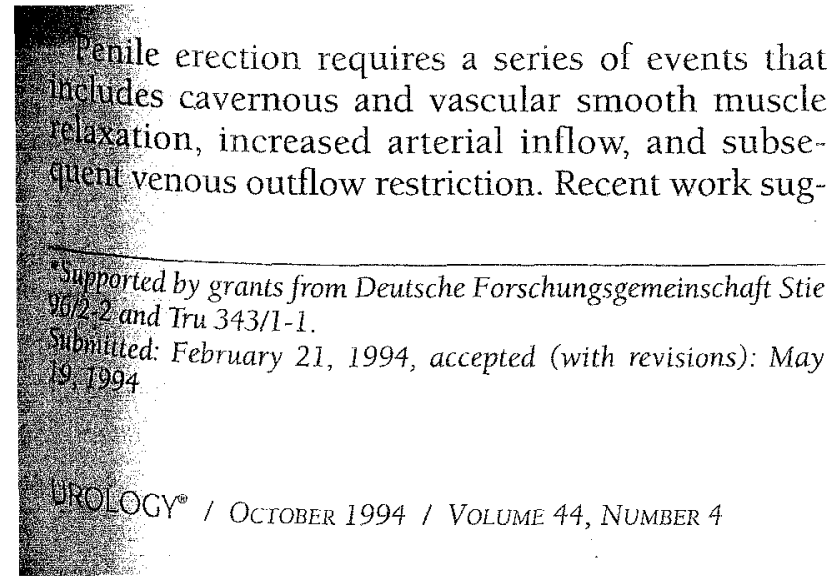

gests that the initial step, cavernous and vascular smooth muscle relaxation, is mediated by the synthesis and release of nitric oxide from nerves innervating vascular and cavernous smooth muscles. $^{1-4}$ Therefore, the use of the L-arginine/nitric oxide pathway seems to be a possible approach in the treatment of erectile dysfunction. Linsidomine chlorhydrate (SIN-1; Corvasal Intracoronaire, Hoechst, France), the active hepatic metabolite of 
molsidomine (N-ethoxycarbomyl-3-morpholinosydninimine), is believed to liberate nitric oxide nonenzymatically (nitric oxide donor). Theoretically, a nitric oxide donor may be superior to other vasoactive drugs because it may resemble more closely the physiologic sequence of events in penile erection. Our preliminary results with the intracavernous application of SIN-1 suggested a possible role in the treatment of patients with erectile dysfunction. ${ }^{5}$ We now report our extended follow-up with SIN-1 in the diagnosis and treatment of patients with erectile dysfunction.

\section{MATERIAL AND METHODS}

All patients underwent a comprehensive and standardized workup for erectile dysfunction, including a detailed case history, physical examination, sexual case history (questionnaire), routine blood tests, pharmaco-Doppler ultrasound, corpus cavernosum electromyogram, ${ }^{6}$ and pharmacotesting. When indicated, pharmacocavernosometry and pharmacocavernography were carried out ( 12 patients).

All 113 patients ( 8 patients with primary and 105 patients with secondary impotence) and 10 normal control subjects received $1 \mathrm{mg}$ SIN-1 intracavernously. Of 113 patients, 71 (62.8\%) received additional, at least three, injections of a mixture of papaverine $(15 \mathrm{mg} / \mathrm{mL})$ and phentolamine $(0.5$ $\mathrm{mg} / \mathrm{mL}$ ) (P/P) prior to pharmacotesting with SIN-1. Increasing doses of 0.25 to $2.0 \mathrm{~mL}$ were given according to the erectile response. All injections were given in a supine position. Responses to $\mathrm{P} / \mathrm{P}$ and SIN-1 were evaluated by a urologist after 10,20 , and 30 minutes by inspection and palpation and graded as follows: $E 0$, no response; $E 1$, slight tumescence; E 2, medium tumescence; E 3, full tumescence but no rigidity; $E$ 4, full tumescence with medium rigidity, sufficient for intercourse; E 5, full rigid erection. Forty-eight SIN-1 responders entered an autoinjection program with SIN-1. All patients were seen as outpatients after the first 10 injections and thereafter following each series of 25 injections. At follow-up visits, a history and physical examination and routine blood tests were taken

All patients as well as the normal control subjects were extensively informed of the study and the possible side effects (prolonged erections, cavernous fibrosis, infection, cavernous necrosis, and systemic side effects such as hypotension). Written consent was obtained from all participants. The study was approved by the Ethics Committee of the Medizinische Hochschule Hannover.

\section{RESULTS}

The mean patient age was $48.9 \pm 11.9$ years Erectile dysfunction was prevalent for $56 \pm 27 \%$ months. The mean age of the volunteers (controt subjects with normal erectile function) was 34 8.4 years. The patients' past medical histories cluded nicotine abuse ( 25 patients), peripheral ve cular disease (21 patients), hypertension ( 17 , tients), diabetes (17 patients), hyperlipidemia (12 patients), pelvic trauma (9 patients), and alcohol abuse ( 6 patients). In 27 patients the medical bis tory was not contributory.

Following intracavernous administration SIN-1, all normal control subjects had full rigi erections (E 5) lasting 40 to 70 minutes, whice spontaneously resolved. No complications or side effects such as penile pain, hemorrhage, infectiot: or prolonged erections occurred. Of the patients: with erectile dysfunction, 40 had E 5, 38 had E 4 20 had E 3, 14 had E 2, and 1 had E 1 responses : intracavernous SIN-1 pharmacotesting. Again, side effects were noted.

Electromyographic patterns in patients respond ing with $\mathrm{E} 4$ and $\mathrm{E} 5$ erections to SIN-1 (32 noi mal, 40 pathologic) did not differ significanty from patients responding with $\mathrm{E} 1$ to $\mathrm{E} 3$ erections (18 normal, 23 pathologic). With respect to ris factors, no differences were found between to sponders and nonresponders except in patients fort lowing pelvic trauma and patients with primar erectile dysfunction. All 9 patients after pely. trauma (mean age, $30.8 \pm 6.2$ years) and all $8 \mathrm{p}$ tients with primary erectile dysfunction (mean age $35.6 \pm 9.6$ years) responded to SIN-1 with E 400 E 5 erections. Nine of 12 patients $(75 \%)$ who ut derwent pharmacocavernosometry and pharmac cavernography for suspected venous leakage d not achieve erections sufficient for intercourse ( 1 to $E 3$; mean age, $56.3 \pm 7.6$ years).

of 113 patients, $71(62.8 \%)$ also underwe pharmacotesting with increasing doses of a $\mathrm{mi}$ ture of papaverine $(15 \mathrm{mg} / \mathrm{mL})$ and phentolamin $(0.5 \mathrm{mg} / \mathrm{mL})$. Of these 71 patients, $64(90.1 \%)$ h E 4 or E 5 erections, including all patients who showed adequate response to SIN-1 and $20 \mathrm{of} 2$ patients $(74.1 \%)$ who failed. Mean doses of P/P responders and nonresponders to SIN-1 were 0.6 0.3 and $1.5 \pm 0.5 \mathrm{~mL}$, respectively $(\mathrm{p}<0.0001$, sil dent's $t$ test). Of 44 SIN-1 responders, 6 (136\% and 1 of 27 SIN-1 nonresponders (4\%) expee enced prolonged erections for more than $240 \mathrm{mil}$ utes with $\mathrm{P} / \mathrm{P}$.

The 48 SIN-1 responders performed a total 1160 self-injections (10 to 150 injections/patien mean, 24.1). No complications such as penile pal 
osis, infection, or prolonged erections were d. All patients with the exception of 3 15\%) were satisfied with their response to 1. Three patients withdrew from the study bee the quality of the erectile responses to SIN-1 eased.

\section{COMMENT}

I. exently, nitric oxide has been identified as a me the of cavernous smooth muscle relaxation and le erection in vitro and in vivo. ${ }^{1-4}$ Nitric oxide nthesized from L-arginine by nitric oxide syn(NOS); it acts on guanylate cyclase activawhich subsequently leads to an intracellular norease of cyclic guanosine 3',5' monophosphate (6VIP). The intracellular receptor for cGMP is atwp dependent protein kinase $G$, which is beleared to phosphorylate ion channels, causing in4. (t) (t) thation. SIN-1 is a drug approved for the treatthe 1 t of coronary spasms and for angiography of eronary arteries. It is believed to liberate nitric axide nonenzymatically. The recommended dosage 40. angiography is 0.4 to $1 \mathrm{mg}$. Since our initial 4atashowed a dose-dependent response to SIN-1 17t more favorable results with $1 \mathrm{mg}$, all subsequent patients received $1 \mathrm{mg}$.

Inour present series 35 of 113 patients (31\%)

VIfled to respond with erections sufficient for in1croourse. In our initial report ${ }^{5}$ only $21 \%$ failed; 115, our present data are somewhat less favorable. Xs may be attributed to the higher percentage of dents with assumed neurogenic erectile dysfirction in our first 63 patients, since patients with 110 ominantly neurogenic impotence, that is, diatres and patients after pelvic trauma, tend to reond better to intracavernous pharmacotherapy. ${ }^{7}$ We fact that nonresponders to SIN-1 showed a 4ancy toward multiple risk factors and 20 of 27 Hollesponders (74.1\%) achieved erections suffiCrevt for intercourse with $\mathrm{P} / \mathrm{P}$ indicates that $\mathrm{P} / \mathrm{P}$ 19. 6 be preferable to SIN-1 in patients with a mulWrorial origin of erectile dysfunction, that is, paMents with significant arterial vascular disease and Whetic neuropathy. The higher smooth muscle reang potential of $\mathrm{P} / \mathrm{P}$ is also reflected by the fact ar. SIN - 1 nonresponders needed a significantly 4yer dosage of $\mathrm{P} / \mathrm{P}$ than nonresponders to induce arection sufficient for intercourse $(1.5 \pm 0.5 \mathrm{vs}$ 9.6 $+0.3 \mathrm{~mL} ; \mathrm{p}<0.0001)$. Our observation that 11. 1 is not effective in the majority of patients Minvenous leakage is in accordance with the findIf of others. ${ }^{8}$ If venous leakage is a symptom of Hemplete cavernous relaxation, further support Wiven to the assumption that SIN-1 causes submaximum cavernous relaxation. ${ }^{9}$ In contrast, SIN-1 gives excellent results in patients with (assumed) relatively intact cavernous tissue, that is, younger patients with primary erectile dysfunction and erectile dysfunction due to pelvic trauma.

In 6 of 44 SIN-1 responders (13.6\%) prolonged erections were seen with P/P. In contrast, SIN-1 did not cause any prolonged erections, even in normal subjects and in patients who needed only minimum amounts of P/P. Therefore, we consider SIN-1 the drug of choice in patients with proven or suspected increased sensitivity to other vasoactive agents. In addition, SIN-1 may prove to be the drug of choice in other subgroups of patients in the future (ie, impotence after pelvic surgery). If SIN-1 fails to induce a satisfactory erectile response, other agents, such as $\mathrm{P} / \mathrm{P}$ or prostaglandin $\mathrm{E}_{1}$, should be administered. Possible explanations for the absent priapismogenic potential of SIN-1 may be a more physiologic induction of erection and the rapid local metabolism of nitric oxide. ${ }^{10}$

After up to 150 injections/patient, no cavernous fibrosis was noted; with respect to local side effects such as intrapenile discomfort or pain, SIN-1 compares favorably to prostaglandin $\mathrm{E}_{1}$ and the combination of papaverine and phentolamine. With prostaglandin $E_{1} 20 \%$ to $40 \%$ of patients experience penile pain and with $\mathrm{P} / \mathrm{P}$, although less intense, most patients report a slight burning sensation during administration. ${ }^{11}$ With SIN-1, no patients reported such a discomfort, which may indicate that the substance is well tolerated by the cavernous tissue. This is also supported by the fact that no inflammatory or fibrous reactions were seen after multiple intracavernous injections in the rabbit model. ${ }^{12}$

Currently, all patients at our institution undergoing intracavernous pharmacotesting receive 1 $\mathrm{mg}$ SIN-1. In case of a satisfactory erectile response, all patients are counseled to enter a self-injection program with SIN-1 for a maximum reduction of possible side effects. Patients not responding to SIN-1 are advised to undergo pharmacotesting with increasing doses of papaverine plus phentolamine. Responders continue with this regimen, whereas nonresponders are offered a trial with intracavernous calcitonin gene-related peptide plus prostaglandin $\mathrm{E}_{1}$, since this combination was shown to be effective in the majority of $\mathrm{P} / \mathrm{P}$ nonresponders. ${ }^{13}$

In conclusion, our data suggest that intracayernous SIN-1 is safe and efficacious in the majority of patients with erectile dysfunction; however, it has a lower smooth muscle relaxing potential than a combination of papaverine and phentolamine. 
The fact that no prolonged erections were seen even in patients with a past history of priapisms may be explained by the more physiologic induction of erection with a nitric oxide donor and a rapid intracavernous decomposition of SIN-1.

\author{
Michael C. Truss, M.D. \\ Department of Urology \\ Medizinische Hochschule Hannover \\ Konstanty-Gutschow-Str. 8 \\ 3062.3 Hannover, Germany
}

ACKNOWLEDGMENT. To Nicola van Dornick for review of the linguistic style.

\section{REFERENCES}

1. Ignarro LJ, Bush PA, Buga GM, Wood KS, Fukuto JM, and Rajfer J: Nitric oxide and cyclic GMP formation upon electrical field stimulation cause relaxation of corpus cavernosum smooth muscle. Biochem Biophys Res Commun 170: 843-850, 1990.

2. Holmquist F, Stief CG, Jonas U, and Andersson KE: Effect of the nitric oxide synthase inhibitor NG-nitro-L-arginine on the erectile response to cavernous nerve stimulation in the rabbit. Acta Physiol Scand 143: 299-304, 1991.

3. Rajfer J, Aronson WJ, Bush PA, Dorey FJ, and Ignarro LJ: Nitric oxide as a mediator of relaxation of the corpus cavernosum in response to nonadrenergic, noncholinergic neurotransmission. N Engl J Med 326: 90-94, 1992.

4. Burnett AL, Lowenstein CJ, Bredt DS, Chang TS, and Snyder SH: Nitric oxide: a physiologic mediator of penile erection. Science 257: 401-403, 1992.
5. Stief $C G$, Holmquist F, Djamilian M, Krah H, Ander $\mathrm{KE}$, and Jonas U: Preliminary results with the nitric ox donor linsidomine chloralhydrate in the treatment of hui erectile dysfunction. J Urol 148: 1437-1440, 1992.

6. Stief CG, Djamilian M, Schaebsdau F, Truss MC, Sehh RW, Abicht JH, Allhoff EP, and Jonas U: Single potenk analysis of cavernous electric activity-a possible diagnos of autonomic impotence? World J Urol 8: 75-79, 1990.

7. Jünemann KP: Pharmacotesting in erectile dysfuncti in Jonas U, Thon WF, and Stiel CG (Eds): Erectile Dysfin tion, Berlin, Springer Verlag, 1991, pp 104-114.

8. Wegner HE, and Knispel HH: Effect of nitric ox donor, linsidomine chlorhydrate, in treatment of human eres tile dysfunction caused by venous leakage. Urology 4 409-411, 1993.

9. Carrier S, Brock G, Kour NW, and Lue TTF: Pat physiology of erectile dysfunction. Urology 42: 468-48 1993.

10. Bush PA, Gonzalez NE, and Ignarro LJ: Biosynthe of nitric oxide and citrulline from L-arginine by constituix nitric oxide synthase present in rabbit corpus cavernosume Biochem Biophys Res Commun 186: 308-314, 1992.

11. Wetterauer U: Intracavernous pharmacotherapy erectile dysfunction, in Jonas U, Thon WF, and Stief (Eds): Erectile Dysfunction, Berlin, Springer Verlag, 1991/ 221-235.

12. Meyer MF, Taher A, Krah H, Staubesand J, Becket ( Kirchner M, Mayer B, Jonas U, Forssmann WG, and Stief Co Intracavernous application of $\mathrm{SIN}-1$ in rabbit and man: faix tional and toxicological results. Ann Urol 27: 179-182, 199

13. Djamilian M, Stief CG, Kuczyk M, and Jonas U: low up results of a combination of calcitonin gene-relaiso peptide and prostaglandin E1 in the treatment of erectiledys function. J Urol 149: 1296-1298, 1993. 